\title{
The mating behavior and reproduction performance in a multi-sire mating system for pigs
}

\author{
A.G. Kongsted *, J.E. Hermansen \\ Department of Agroecology, Faculty of Agricultural Sciences, University of Aarhus, P.O. Box 50, DK-8830 Tjele, Denmark \\ Received 9 November 2006; received in revised form 14 January 2008; accepted 19 January 2008
}

\begin{abstract}
An important aim of organic animal production is to allow natural animal behaviour. Regarding reproduction techniques, artificial insemination is permitted but natural mating is preferred. The outdoor multi-sire system, where the sows are placed in large paddocks with a group of boars, is one example of a service system, which complies well with the organic ideals of facilitating natural animal behavior. However, very little knowledge is available about such system. Seven groups of in total of 47 sows and 31 boars were observed to study the mating behavior in an outdoor multi-sire mating system and the subsequent reproduction results. The time of start of courtship, behavior and the cause of disruption if the courtship was terminated, were recorded each time a boar courted a sow. All aggressive interactions between the boars were also recorded to estimate the boar ranking order. The observations revealed numerous poor quality matings, a huge variation in the number of times sows are mated, and overworked boars. Only $35 \%$ of all copulations lasted $2 \mathrm{~min}$ or more and $63 \%$ of all copulations were disrupted, mainly by competitor boars. The higher social status of the boar, the more copulations did it disrupt $(p<0.05)$. The outcome was an unacceptable variation in reproduction results. Only $71 \%$ of all estrus sows conceived, corresponding to a pregnancy rate of $77 \%$ of all mated sows. A large inter-group variation in reproduction performance was observed, indicating scope for improvements. In some groups all sows showed estrus and all sows conceived. Recommendations for improvement of the system are proposed.
\end{abstract}

(C) 2008 Elsevier Inc. All rights reserved.

Keywords: Multi-sire mating; Mating behavior; Mating quality; Reproduction; Organic production

\section{Introduction}

There is an increasing interest in organic production throughout Europe [1]. In Denmark, for instance, the consumption of organic pork has increased by $100 \%$ from 2003 to 2005 [2]. Within the EU, organic pig production must comply with the rules specified in Council Regulation (EC) No. 1804/1999. The legislation aims at providing environmental conditions that allow natural animal behavior, these involving access to

\footnotetext{
* Corresponding author. Tel.: +45 8999 1252; fax: +45 89991200.

E-mail address: anneg.kongsted[a]agrsci.dk (A.G. Kongsted).
}

out-door areas. Regarding reproduction techniques, artificial insemination is permitted but natural mating is preferred.

In Denmark, the service-facilities in organic sow herds are often indoors based on artificial insemination and group-housing of sows within limited space and, as such, do not differ markedly from service facilities and conditions in many conventional sow herds. However, in other countries, e.g. in the UK [3], the organic production is mainly based on natural mating outdoor, supervised or unsupervised.

The outdoor multi-sire system is one example of a service system, which complies well with the organic ideals of facilitating natural animal behavior. In a 
multi-sire mating system the sows are placed in large service paddocks at weaning together with a group of boars. This system differs in several aspects compared to the service system based on artificial insemination or supervised natural mating, where one boar is placed in a small pen with one estrus sow [4-7]. In a multi-sire mating system, there is no control of the individual mating, because the copulations take place with no or very little supervision. The reproduction outcome depends to a large degree on appropriate mating behavior of the sows and the boars. Finally, the grouphousing of the animals during mating may result in competition for the available resources, including sexual partners [6].

One short-range study carried out in an outdoor sow unit in the United Kingdom indicated that the system is highly inefficient because of very few successful matings; however, no reproduction results were reported [8]. In general, very little knowledge is available about outdoor multi-sire systems.

The objectives of this investigation were to study (1) the mating behavior of the sows and boars throughout a year in an outdoor multi-sire mating system and (2) the subsequent reproduction results.

\section{Materials and methods}

\subsection{Herd and animals}

The study was conducted over a 10-month period from July 2005 to April 2006 in an organic sow herd in central Jutland, Denmark. The herd numbered 200 multiparous Landrace $\times$ Large White sows and weaning took place every second week. The sows farrowed outdoors in individual paddocks and weaning was at approximately 7 weeks of lactation. At weaning the sows were sorted according to body size (large and small) into two stabile groups of five to nine sows. Small sows were mainly first and second parity sows (ten first parity, nine second parity, two third parity and one fourth parity sow). Each group was placed in an integrated service and pregnancy paddock of approximately $4000 \mathrm{~m}^{2}$. Two to four days after weaning, Duroc $\times$ Hampshire crossbreds boars aged between 1 and 2 years were introduced into the paddocks. The boars were grouped according to size/estimated weight. Two weeks after weaning, all boars were removed and a new boar was introduced to "catch" sows that returned to estrus. The new boar stayed in the paddock until 7 weeks after weaning. The sows stayed in the paddocks until 10 days before expected farrowing. The sows were fed 50-60 ME MJ day ${ }^{-1}$ the first 3 weeks after weaning and $20-40 \mathrm{ME} \mathrm{MJ} \mathrm{day}^{-1}$ thereafter, depending on season and grass cover. The animals were fed once daily, usually between 7 and 10 a.m.

\subsection{Behavioral observations, rank determination of boars, estrus and pregnancy diagnosis}

Behavioral observations were carried out on four batches weaned in July, October, January and March, respectively, a total of 47 sows and 31 boars. The number of sows in each group varied from five to nine and the boar:sow ratio from $1: 3$ to $1: 1$ on the observation days (see Table 1 for number of sows and boars in each group for each observation day). The size and the structure of the groups reflected usual management procedure at the farm. The behavioral observations were performed from the ground or, if necessary, from an elevated observation post. It was always possible to overlook the two paddocks simultaneously. Sometimes binoculars were used. Observers worked 5-6 h shifts.

Observations took place on days 3-7 (weaning day $=$ day 0) except for the observations in October, which took place on days 4-7. The observations began at dawn and continued until dark. One exception was the first observations period (July), when the observations were carried out $24 \mathrm{~h} /$ day, because we expected some sexual activity during darkness due to the relatively high temperatures in the daytime as previously observed in a Japanese study [4]. When necessary, an electric torch was used to identify animals

Table 1

Number of boars and sows on days 4-7 in each of the two groups for the four observation periods

Observation period Group-type ${ }^{\mathrm{a}}$ No. of boars/no. of sows

\begin{tabular}{|c|c|c|c|c|c|c|}
\hline & & Day 3 & Day 4 & Day 5 & Day 6 & Day 7 \\
\hline \multirow[t]{2}{*}{ July } & $\mathrm{L}$ & $3 / 6$ & $3 / 6$ & $3 / 6$ & $2 / 6$ & $3 / 6$ \\
\hline & $\mathrm{S}$ & $4 / 6$ & $4 / 6$ & $4 / 6$ & $4 / 6$ & $4 / 6$ \\
\hline \multirow{2}{*}{ October } & $\mathrm{L}$ & $0 / 5$ & $5 / 5$ & $5 / 5$ & $3 / 5$ & $3 / 5$ \\
\hline & $\mathrm{S}$ & $0 / 8$ & $4 / 8$ & $4 / 9$ & $6 / 9$ & $6 / 9$ \\
\hline January & $\mathrm{L}^{\mathrm{c}}$ & $6 / 8$ & $6 / 8$ & $6 / 8$ & $6 / 8$ & $4 / 8$ \\
\hline \multirow[t]{2}{*}{ March } & $\mathrm{L}$ & $4 / 6$ & $4 / 6$ & $4 / 6$ & $5 / 6$ & $5 / 6$ \\
\hline & $\mathrm{S}$ & $5 / 7$ & $5 / 7$ & $5 / 7$ & $5 / 7$ & $4 / 7$ \\
\hline
\end{tabular}

\footnotetext{
${ }^{\mathrm{a}}$ L: Large sows, S: small sows.

b The number of boars and sows in the group could vary between days because some animals were able to crawl under the fence and move from one paddock to another.

${ }^{c}$ The animals moved freely between the two paddocks due to snow, which reduced the power of the electric fence (all the sows could be characterised as large sows compared to the other observation periods).
} 
and activity during night. For observation period 2, 3 and 4, the observations began at 6,7.30 and 6 a.m. and continued until 8,5 and 8 p.m., respectively.

To allow individual identification during behavioral observations, the sows and boars were sprayed with a colour code on their backs before introduction to the service paddock. Each time a boar courted a sow for more than $5 \mathrm{~s}$, the following information was recorded: boar ID, sow ID, time of start of courtship, behavior and, if the courtship was terminated due to another sow or boar, the ID of the terminator. The behaviors observed were classified into nine categories as shown in Table 2. Copulation was defined as disrupted if the cause of termination was "the sow walked away", "another boar intervened", "another sow intervened" and "the sow collapsed". If intromission took place, the duration of the copulation was also recorded. If the copulation lasted for $2 \mathrm{~min}$ or more and the sow was immobile during copulation, the quality of the mating was defined as "fair" (modified after [6]).

The winning and losing animal of all aggressive interactions between the boars was recorded during the observation period. Interactions included threats, pushes, bites and the characteristic "shoulder press" $[10,11]$. The boar able to displace all other boars in the mating group was given the top rank position (rank 1). The second rank was given to the boar that was able to displace all boars except the top ranked, etc.

The sows were checked for signs of estrus each day during the observation period. Signs of estrus were defined as swelling and colouration of the vulva, restlessness, showing interest in the boars, mounting other sows and showing the standing reaction [12].
Table 3

Temperature and rainfall during the observation periods (24-h values)

\begin{tabular}{lllll}
\hline & July & October & January & March \\
\hline $\begin{array}{l}\text { Temperature, average } \\
\text { (and min/max }\end{array}$ & $15(10 / 22)$ & $13(8 / 18)$ & $0(-12 / 5)$ & $5(-1 / 10)$ \\
temperature in \\
$\begin{array}{l}\text { parenthesis) }\left({ }^{\circ} \mathrm{C}\right) \\
\text { Rainfall }(\mathrm{mm} / \text { day) }\end{array}$ & 9 & 0 & 0 & 7 \\
\hline
\end{tabular}

Five weeks after weaning, the observed sows were tested for pregnancy with an Ultrasonic pregnancy diagnosis scanner (Agroscan A8, EuroVet ApS).

\subsection{Climatic conditions}

The climatic conditions during the four observation periods are presented in Table 3.

\subsection{Statistical analyses}

The association between categorical variables, e.g. group type (large vs. small sows) and pregnancy diagnosis (positive or negative), was tested using a Chisquare test. If some of the expected values were below five and the contingency table was a $2 \times 2$ table, we used a two-tailed Fisher's exact test instead. A Chisquare test (goodness-of-fit test) was also used to investigate whether frequency distributions, e.g. the frequency distribution for total number of copulations, depended on group type. In some of the Chi-square tests, one or more expected values were below 5. This may reduce the validity of the test [13]. However, the $p$ values were far above 0.05 in all the analyses in question

Table 2

Definitions of the behavioural elements recorded for each courtship

\begin{tabular}{|c|c|}
\hline Behaviour & Definition \\
\hline 1. Interest & $\begin{array}{l}\text { Following (boar follows a sow), head to head (boar's head } \\
\text { to sow's head), sniffing (boar sniffs and licks a sow's } \\
\text { ano-genital region) or nosing (boar presses his nose } \\
\text { against sow's head, shoulder or flank) }{ }^{\text {a }}\end{array}$ \\
\hline 2. Standing reaction & Sow stands immobile, arches her back and cocks the ear ${ }^{\mathrm{b}}$ \\
\hline 3. Mounting & $\begin{array}{l}\text { Boar has both legs raised off the ground and touches the } \\
\text { sow he intends to mount }\end{array}$ \\
\hline 4. Copulation & Intromission occur \\
\hline 5. Sow walks away & The sow terminated the courtship by walking away \\
\hline 6. Boar walks away & The boar terminated the courtship by walking away \\
\hline 7. Another boar intervened & The courtship is terminated because another boar intervened \\
\hline 8. Another sow intervened & The courtship is terminated because another sow intervened \\
\hline 9. The sow collapsed & The sow collapsed under the weight of the boar \\
\hline
\end{tabular}

\footnotetext{
a $[4,5]$.
}

b [9]. 
and it is unlikely that wrong conclusions (because of small sample sizes) were drawn.

A two-tailed Wilcoxon rank-sum test was used to examine differences between the two group types in interval data, e.g. the total number of copulations per sow, whereas a Kruskal-Wallis test was used to examine differences between boar social status (rank 1, 2, 3 and $\geq 4$ ) in interval data, e.g. number of copulations the boar interrupted.

All analyses were performed in $\mathrm{SAS}^{\circledR}$ [14]. We used the FREQ procedure for the Fisher's exact test and the $\chi^{2}$-tests, whereas Wilcoxon rank-sum tests and Kruskal-Wallis tests were performed using the NPAR1WAY procedure.

\section{Results}

\subsection{Diurnal pattern of copulation activity}

The diurnal patterns of copulation activity and total sexual activity (copulations, mounts, and boars showing interest in a sow) on days 4-5 in the four observation periods are shown in Fig. 1. The distribution of copulations as well as the general activity throughout the day differed markedly between the four observation periods without any clear, repeatable, diurnal pattern.

\subsection{The number of copulations on each day of the observation period}

Fig. 2 illustrates the copulation activity in the two group types. In large sows, most of the copulation activity occurred on day 4 after weaning, whereas for small sows, day 5 after weaning showed the highest level of activity. These results suggest that the small sows, on average, came into estrus later than the larger, and probably older, sows. In total, $87 \%$ of all copulations occurred on days 4-5 after weaning.

\subsection{Mating frequency and quality (sows)}

Table 4 presents the number of copulations per estrus sow for each group together with the percentage of copulations interrupted by "another boar", "another sow", due to "collapse of the sow" and due to the "sow walking away".

The mean total number of copulations per estrus sow was 5.49 with a range of 1.25-9.33 between the seven groups, while the mean number of copulations lasting for 2 min or more per estrus sow was only 1.89 with a range of 0.5-5.0. There was no significant effect of group type (large vs. small sows) on the total number of copulations per sow (5.5 vs. 6.1, Wilcoxon rank sum: $Z=0, p=1$ ) or of number of copulations lasting for 2 min or more per sow (1.8 vs. 2.5, Wilcoxon rank sum: $Z=0.18, p=0.9$ ).

The frequency distributions for total number of copulations per estrus sow and number of copulations lasting for $2 \mathrm{~min}$ or more are shown in Fig. 3. The distributions did not differ significantly between groups

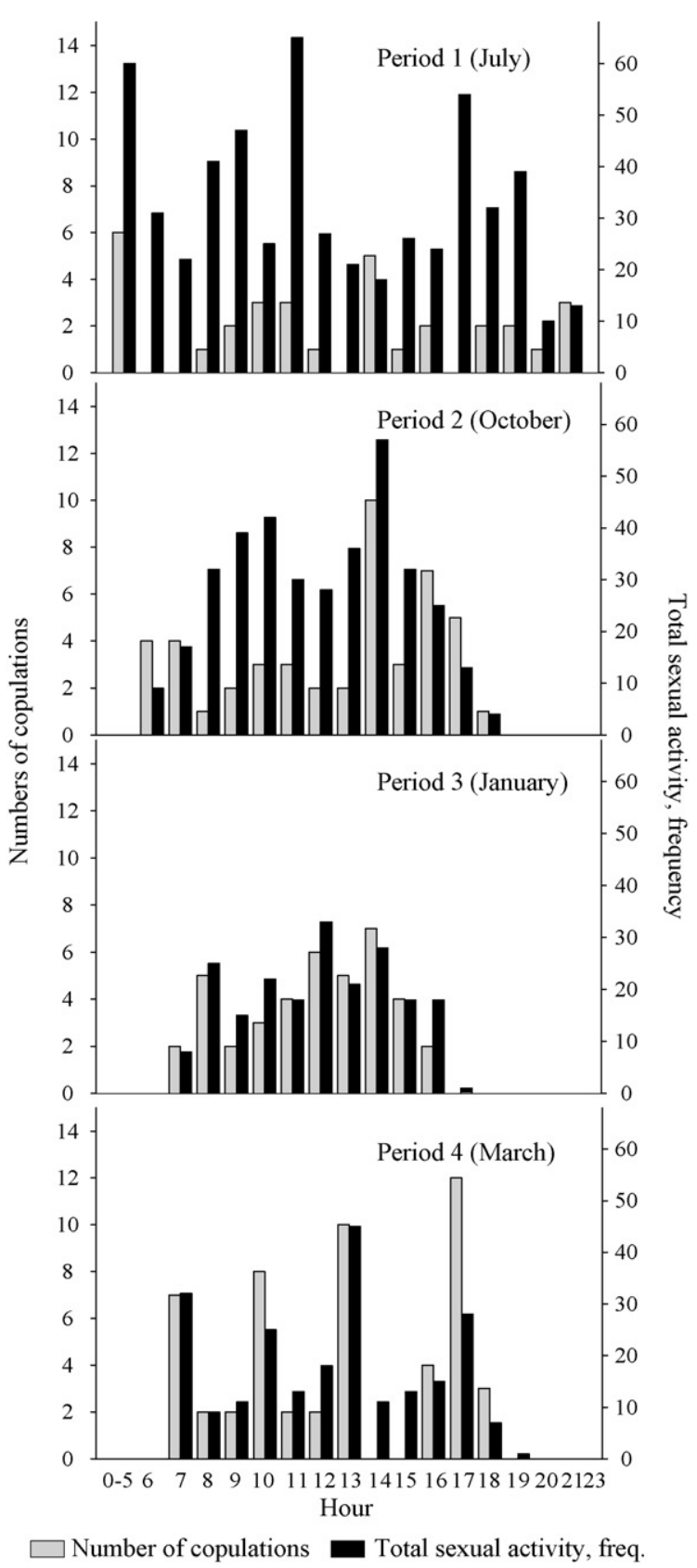

Fig. 1. The diurnal patterns of the overall sexual activity and copulation activity in the four observation periods (day 4 and day 5). 
Table 4

The total number of copulations per estrus sow (divided according to duration) and the percentage of copulations interrupted due to another boar, another sow, collapse of the sow or the sow walking away, respectively, for each group in the four observation periods

\begin{tabular}{|c|c|c|c|c|c|c|c|c|c|}
\hline \multirow[t]{2}{*}{ Observation } & \multirow[t]{2}{*}{ Group-type $^{\mathrm{a}}$} & \multicolumn{4}{|c|}{ No. of copulations per estrus sow } & \multicolumn{4}{|c|}{ Interruptions, $\%$ of all copulations } \\
\hline & & $<1 \min$ & $1-2 \min$ & $\geq 2 \min$ & Total $^{\mathrm{b}}$ & Another boar & Another sow & Sow collapses & Sow walks away \\
\hline \multirow[t]{2}{*}{ Jul } & $\mathrm{L}$ & 0.25 & 0.25 & 0.50 & 1.25 & 0 & 20 & 0 & 20 \\
\hline & $\mathrm{S}$ & 3.2 & 0.17 & 1.83 & 5.33 & 34 & 6 & 19 & 28 \\
\hline \multirow[t]{2}{*}{ Oct } & $\mathrm{L}$ & 1.80 & 0.60 & 3.0 & 5.40 & 37 & 0 & 15 & 7 \\
\hline & $\mathrm{S}$ & 2.33 & 0.56 & 0.78 & 3.78 & 56 & 0 & 15 & 3 \\
\hline Jan & $\mathrm{L}$ & 4.50 & 1.00 & 2.33 & 7.83 & 19 & 2 & 0 & 23 \\
\hline \multirow[t]{2}{*}{ Mar } & $\mathrm{L}$ & 4.00 & 1.50 & 1.50 & 7.50 & 43 & 4 & 0 & 4 \\
\hline & $\mathrm{S}$ & 2.00 & 2.00 & 5.0 & 9.33 & 53 & 3 & 13 & 3 \\
\hline \multirow[t]{3}{*}{ All data } & $\mathrm{L}$ & 2.79 & 0.84 & 1.95 & 5.74 & 32 & 3 & 7 & 14 \\
\hline & $\mathrm{S}$ & 2.56 & 0.67 & 1.83 & 5.22 & 45 & 3 & 12 & 12 \\
\hline & $\mathrm{L}+\mathrm{S}$ & 2.68 & 0.76 & 1.89 & 5.49 & 38 & 3 & 9 & 13 \\
\hline
\end{tabular}

${ }^{\mathrm{a}} \mathrm{L}$ : large sows, S: small sows.

b The total number of copulations is not always equal to the sum of copulations lasting $<1 \mathrm{~min}$, between 1 and 2 min and more than 2 min because there are few copulations that we do not know the duration of.

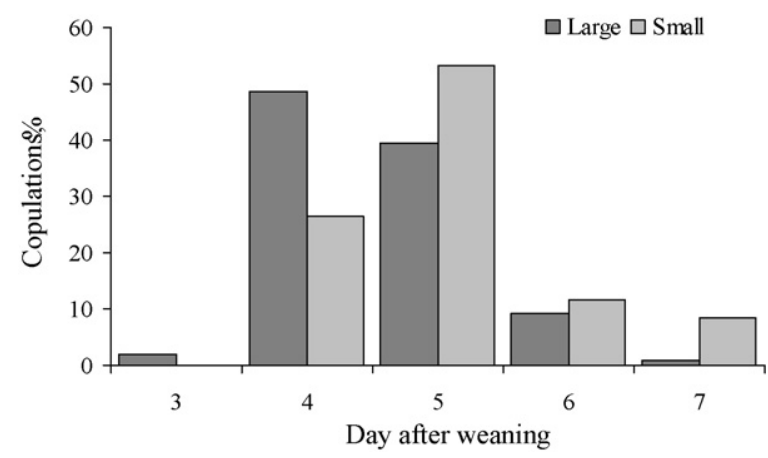

Fig. 2. The percentage copulations on each day of the observation period for large and small sows, respectively (day $0=$ the day of weaning).

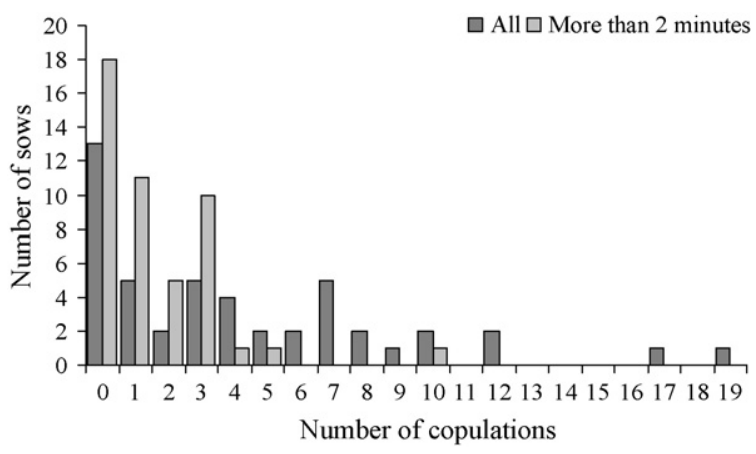

Fig. 3. The frequency distributions for the total number of copulations per sow and the number of copulations lasting more than 2 min per sow.

with large sows and groups with small sows (total numbers: $\chi^{2}=9.1, \mathrm{df}=13, p=0.8$; of more than $2 \mathrm{~min}$ : $\left.\chi^{2}=4.7, \mathrm{df}=6, p=0.6\right)$. Three of the 13 sows, which were not mated, had shown signs of estrus. As many as
18 sows had no copulations lasting 2 min or more, even though they had shown signs of estrus. This corresponds to $22 \%$ of all the sows in estrus.

\subsection{Mating frequency and quality (boars)}

Fig. 4 illustrates the frequency distribution for the total number of copulations together with the distribution of copulations lasting $2 \mathrm{~min}$ or more for the 31 boars. There were no significant differences between groups with small and large sows regarding these distributions (total numbers: $\chi^{2}=14.7, \mathrm{df}=14, p=0.4$; more than 2 min: $\chi^{2}=4.7, \mathrm{df}=7, p=0.7$ ). Only two boars had no copulations at all, but eight boars had no mating lasting for $2 \mathrm{~min}$ or more. The mean total number of copulations per boar was 6.5 with a range of 1.7-8 between the seven groups, while the mean number of copulations lasting for 2 min or more per

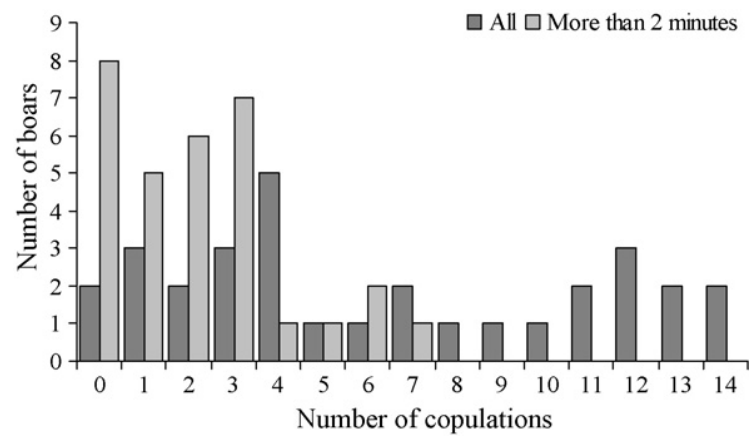

Fig. 4. The frequency distributions for the total number of copulations per boar and the number of copulations lasting 2 min or more per boar. 
boar was only 2.3 varying from 0.7 to 3.0 between the groups. There was no significant effect of group type (large vs. small) on total number of copulations per boar (5.6 vs. 7.1, Wilcoxon rank sum: $Z=1.1, p=0.3$ ) or of number of copulations lasting for $2 \mathrm{~min}$ or more per boar (1.9 vs. 2.5 , Wilcoxon rank sum: $Z=0.7, p=0.5$ ).

\subsection{Disrupted copulations}

In total, $63 \%$ of all copulations were disrupted. This differed markedly between the seven groups from 40 to $90 \%$, and significantly between groups with small and large sows $\left(71 \%\right.$ vs. $\left.56 \%, \chi^{2}=5.1, \mathrm{df}=1, p=0.03\right)$. The main cause of disruption was interruption from other competitor boars as shown in Table 4. The intervention of another boar thus ended $38 \%$ of all copulations. This corresponds to $60 \%$ of all disrupted copulations.

Not surprisingly, the quality of mating was significantly related to whether the copulation was interrupted or not with $76 \%$ of all copulations lasting less than 2 min having been disturbed compared to only $37 \%$ of all copulations lasting 2 min or more $\left(\chi^{2}=29.6\right.$, $\mathrm{df}=1, p<0.0001)$. However, $23 \%$ of all copulations lasting less than 2 min were not disrupted by any of the recorded reasons. It is likely that at least some of these matings were unsuccessful due to some boars having poor boar mating skills (difficulties with maintaining constant intromission), which we observed in several occasions.

\subsection{Effect of boar social status}

Table 5 shows the relation between the boar social status and the mating activity. The total number of copulations was significantly related to the social rank of the boars with boars of rank 1 and 3 having the highest frequencies. Boars of rank 1-3 (68\% of all boars) were accountable for $81 \%$ of all copulations. There was no significant relation between rank order and the number of copulations lasting $2 \mathrm{~min}$ or more (Table 5).

As also evident from Table 5, there was a significant relation between boar social status and the number of copulations the boar interrupted. Boars of rank 1 and 2 ( $45 \%$ of all boars) were responsible for $82 \%$ of all interrupted copulations. In comparison, the subordinate boars $(\geq$ rank 4$)$ were only responsible for $5 \%$ of all interruptions.

The proportion of copulations that were interrupted for individual boars by a competitor boar was significantly affected by boar social status (Table 5). The dominating boars (rank 1) had by far the lowest proportion of interrupted copulations with $15.4 \%$ of all copulations, whereas boars of rank 3 had the highest proportion with $58.3 \%$ of all copulations. Rank order also significantly affected the proportion of copulations that were terminated due to collapse of the sow-the higher social status, the higher the proportion of collapses (Table 5).

\subsection{Reproduction performance}

Table 6 shows the reproduction performances of sows. Thirty-seven sows (79\%) showed estrous behavior within the observation period. Three of these sows were not diagnosed for pregnancy (one sow was culled before pregnancy diagnosis and two sows were impossible to diagnose). Of the remaining 34 sows, only $24(71 \%)$ had a positive pregnancy diagnosis. This

Table 5

The relation between the rank of the boar $(1=$ highest rank $)$ and the number of copulations, proportion of copulations lasting 2 min or more, the number of copulations that the boar interrupted, and the proportion of copulations the boar got interrupted by another boar and due to collapse of the sow, respectively

\begin{tabular}{|c|c|c|c|c|c|}
\hline & Rank 1 & Rank 2 & Rank 3 & $\geq \operatorname{Rank} 4$ & Statistics \\
\hline Number of boars & 7 & 7 & 7 & 10 & - \\
\hline Total number of copulations & 9.3 & 5.9 & 8.6 & 3.4 & $\chi^{2}=8.9, \mathrm{df}=3, p=0.03^{\mathrm{a}}$ \\
\hline Number of copulations lasting 2 min or more & 3.0 & 2.0 & 3.0 & 1.4 & $\chi^{2}=6.6, \mathrm{df}=3, p=0.09^{\mathrm{a}}$ \\
\hline Number of copulations that the boar interrupted & 5.4 & 4.0 & 1.3 & 0.4 & $\chi^{2}=16.2, \mathrm{df}=3, p=0.001^{\mathrm{a}}$ \\
\hline $\begin{array}{l}\text { Proportion of copulations that the boar } \\
\text { got interrupted by another boar, \% of } \\
\text { all copulations }\end{array}$ & 15.4 & 41.5 & 58.3 & 41.2 & $\chi^{2}=25.0, \mathrm{df}=3, p<0.0001^{\mathrm{b}}$ \\
\hline $\begin{array}{l}\text { Proportion of copulations interrupted due } \\
\text { to collapse of the sow, } \% \text { of all copulations }\end{array}$ & 18.5 & 7.3 & 3.3 & 0 & $\chi^{2}=13.6, \mathrm{df}=3, p<0.004^{\mathrm{b}}$ \\
\hline
\end{tabular}

\footnotetext{
${ }^{\mathrm{a}}$ Kruskal-Wallis test (Chi-square approximation)

b Chi-square test.
} 
Table 6

The proportions of sows showing estrus during the observation period and diagnosed pregnant 4 weeks after weaning (L: large sows, S: small sows)

\begin{tabular}{lll}
\hline Observation period Size of the sows & In total & In total \\
\cline { 2 - 3 } & $\mathrm{L}$ & 22 \\
\hline No. of sows & 25 & $1.6(1.4-2.0)$ \\
Average parity no. at weaning (min and max) & $3.9(3.3-5.2)$ & 21 \\
$\quad \begin{array}{l}\text { No. of sows scanned for pregnancy } \\
\text { Proportion of sows showing estrus, \% of all }\end{array}$ & 23 & $82(43-100)$ \\
$\quad$ sows (min and max) & $76(67-100)$ & $65(50-78)$ \\
$\begin{array}{l}\text { Proportion of pregnant sows, \% of estrus } \\
\quad \text { sows (min and max) }\end{array}$ & $76(25-100)$ & $52(17-78)$ \\
$\quad \begin{array}{l}\text { Proportion of pregnant sows, \% of sows } \\
\quad(\text { min and max) }\end{array}$ & $57(17-100)$ & 79 \\
\hline
\end{tabular}

${ }^{\text {a }}$ One sow was culled before scanning (in January) and two sows were impossible to scan (in March). All three sows had shown estrus.

b With known pregnancy status.

corresponds to $55 \%$ of all (diagnosed) sows, varying from $17 \%$ to $100 \%$ between the seven groups.

There were no significant differences between groups with large and small sows in the proportion of sows showing estrous behavior (Fisher's exact test, $p=0.7$ ), sows diagnosed pregnant (of sows in estrus) or of sows diagnosed pregnant (of all sows) $\left(\chi^{2}=0.6\right.$ and 0.1 , respectively, $\mathrm{df}=1, p>0.7$ ).

Sows with a positive pregnancy diagnosis took part in both significantly more total copulations (6.2 vs. 1.6, Wilcoxon rank sum: $Z=-4.6, p<0.001$ ) and copulations of 2 min or more ( 2.0 vs. 0.8 , Wilcoxon rank sum: $Z=-4.0, p<0.001)$ than the sows with a negative pregnancy diagnosis.

\section{Discussion}

Only $35 \%$ of all observed copulations lasted $2 \mathrm{~min}$ or more. This was mainly occasioned by a lot of disrupted copulations (63\% of all copulations). The main cause of disruption was interruption from competitor boars in consistence with earlier studies in indoors [6] and outdoors [8] multi-sire mating systems. In the current study, there was a clear and significant relation between the boar social status and the number of copulations the boar interrupted. The higher the social status, the more copulations the boar interrupted. The boars that represented the three highest-ranking positions also achieved most frequent copulations as previously observed in bulls [15]. However, when looking at the three highest positions in isolation there was no clear relation between the boar social status and the number of copulations. On several occasions, we observed boars with a high social status being more focused on disturbing the other boars than on performing courtship behavior.
Some boars even disrupted copulations without trying to take over the receptive sow when the other boar was chased away. It has been suggested that problems with domination by one boar may be reduced when the boar team consists of littermates reared together [16] or just same-age (size) boars [17]), as observed in multi-sire mating systems for cows and bulls [18]. However this needs to be confirmed in multi-sire mating systems for pigs. It might also be an advantage to reduce the number of boars in the mating teams. Some authors [19] succeeded in improving overall mating quality in an indoor dynamic service system by reducing the number of boars from four to two (by removing the sexually most superior and the most inferior boar). There was, however, no difference in conception rate.

Another consequence of the competition between the boars was that some of the boars became overworked. According to the Danish recommendations, the frequency of ejaculate collections in boars older than 1 year should not exceed seven times a week [20]. Thirty-nine percent of all the boars in the present study were more copulatively active during the 5 days of observation. Especially boars with a high rank carried out more copulations than the recommendations stated. Ninety-two percent of the overworked boars were represented among the three most dominating boars in each group even though top three boars only represented $68 \%$ of all boars. Minimal functional sperm numbers for satisfactory reproduction is unknown for natural mating. However, the high frequency of copulations may heightens the risk of copulations of the overworked boars not resulting in pregnancy due to a low sperm-cell count as indicated in experimental studies with boar ejaculate collection [21]. This may be a contributing 
reason why $19 \%$ of the sows with a negative pregnancy diagnosis received one or more fair quality matings. One way to diminish the problem with overworked boars may be to rotate boar teams for a sexual rest. Practical experience shows that boars easily adapt to a daily rotation system [16].

There were large individual differences between boars in their willingness to court and attempt intromission as also reported by [22-25]. Some boars were very active in, e.g. sensory stimulation of the sows, whereas some boars seemed indifferent even towards estrus sows. Likewise, some boars were very motivated to mount and copulate but had a low success rate due to problems with intromission. The current results therefore emphasize the importance of evaluating boars for sexual behavior before using them in a multi-sire mating system. It may well be possible to implement evaluation methods suitable for use in commercial indoor sow herds [26] in outdoor sow herds after minor modifications.

Of all interrupted copulations, $15 \%$ were due to collapse of the sow because she could not support the weight of the boar. This is a familiar problem in multisire mating systems [6]. Collapse occurred despite the sows and boars having been divided into two groups according to size. The top ranked boar had the highest proportion of copulations terminated due to collapse, indicating a relation between social status and body size/weight.

Studies by $[4,5,22]$ indicate that preferential mating exists between boars and sows, in that some sows are more attractive to boars than others and that some sows are more receptive to specific boars. This may, together with differences in estrus duration between sows, of course also contribute to the large variation in the number of times sows were mated.

Only 55\% of all sows were diagnosed pregnant 5 weeks after weaning. The very poor overall reproduction result was to some extent a consequence of a low estrus occurrence, as $21 \%$ of all sows did not come into estrus the first week after weaning. This is a very high figure compared to a previous study based on conventional sow herds [27] and also considerably higher than observed in other Danish organic sow herds that use artificial insemination or controlled matings [Kongsted, 2007, unpublished data]. Although it is difficult to compare the results from one reproduction cycle with herd averages, the figures indicate problems with estrus occurrence in the present herd. It may be that some sows had already shown estrus before weaning with delayed onset of estrus after weaning as a consequence. Lactational estrus is a well-known problem in organic piglet production due to the long lactation period $[28,29]$ and may even be more frequent in multi-sire mating systems due to a large number of boars and thus a high concentration of, e.g. olfactory boar stimuli. It would appear very important that lactating sows are clearly separated from the mating paddocks and to avoid "escaped" and itinerant boars.

Of all estrus sows, $71 \%$ had a positive pregnancy diagnosis. Seven of the 20 sows, which had a negative pregnancy diagnosis, had been mated. This corresponds to a pregnancy rate of $77 \%$ of all mated sows. Compared to a farrowing rate around $85 \%$ in conventional [30] and organic (Kongsted, 2007, unpublished data) practice based on artificial insemination or controlled matings, this is unsatisfactory. It is possible that some of the sows had been successfully mated and then later lost their pregnancy, but there is no doubt that the low pregnancy rate, to a large extent, was due to the above-mentioned problems related to the functionality of the multisire mating system.

In conclusion, the current study supports the findings of [8] that outdoor multi-sire mating systems may be characterised by numerous poor quality matings; huge variation in the number of times sows are mated, and overworked boars. Our study shows that this leads to an unacceptable variation in reproductive outcome. However, at the same time, the observed variations indicate that there is basis for improvements. In some groups all sows showed estrus and all sows conceived. There is a need for focus on the stringent separation of lactating sows and boars to avoid lactational estrus; selection of boars with adequate sexual motivation, mating skills and good semen quality; the composition and rotation of the boar teams, and to carefully tailor boar size to sow size. If all of these factors are taken into consideration, the multi-sire mating system might well be justified in organic piglet production as a system that promotes natural animal behavior without jeopardising the productivity.

\section{Acknowledgements}

The authors wish to thank the participating farmer and his co-workers for their cooperativeness and kindness. We would also like to thank master student Christina Petersen and technicians Michael Hansen, Henrik K. Andersen and Orla Nielsen for their muchappreciated assistance in carrying out the data collection. 


\section{References}

[1] Hermansen JE, Strudsholm K, Horsted K. Integration of organic animal production into land use with special reference to swine and poultry. Livest Prod Sci 2004;90:11-26.

[2] Statistics Denmark, 2006. http://www.statistikbanken.dk/ OEKO3.

[3] Kelly HRC, Browning HM, Martins AP, Pearce GP, Stopes C, Edwards SA. Breeding and feeding pigs for organic production. In: Proceedings of the 4th NAHWOA workshop; 2001. p. 8693.

[4] Tanida H, Murata Y, Tanaki T, Yoshimoto T. Mounting efficiencies, courtship behaviour and mate preferences of boars under multi-sire mating. Appl Anim Behav Sci 1989;22:245-53.

[5] Tanida H, Miyazaki N, Tanaka T, Yoshimoto T. Selection of mating partners in boars and sows under multi-sire mating. Appl Anim Behav Sci 1991;32:13-21.

[6] Grigoriadis DF, Edwards SA, English PR, Davidson FM. The reproductive behaviour of pigs in a dynamic service system for gilts. Appl Anim Behav Sci 2000;66:203-61.

[7] Grigoriadis DF, Edwards SA, English PR, Davidson FM. The effect of oestrous cycle number, at constant age, on gilt reproduction in a dynamic service system. Anim Sci 2001;72:11-7.

[8] Shaw JM, Edwards SA. A study of courtship and mating behaviour in pigs in an outdoor multi-sire mating system. In: Rutter SM, Rushen J, Randle HD, Eddison HD, editors. Proceedings of the 29th international congress of the international society for applied ethology. 1995. p. 229-30.

[9] Signoret JP. Reproductive behaviour of pigs. J Reprod Fert 1970;(Suppl. 11):105-17.

[10] Beuerle W. Freilanduntersuchungen zum kampf- und sexualverhalten des europäischen wildschweines (Sus scrofa L.). Z Tierpsychol 1975;39:211-58.

[11] Meynhardt H. Mein leben unter wildschweinen. Schwarzwildreport, 8th edition. Neumann Verlag; 1990, $221 \mathrm{pp}$.

[12] Signoret JP. The mating behaviour of the sow. In: Cole DJA, editor. Pig production. London: Butterworth; 1971. p. 295-313.

[13] Siegel S, Castellan NJ. Nonparametric statistics for the behavioural sciences, 2nd edition, McGraw-Hill; 1988, 399 pp..

[14] SAS Institute Inc.. SAS/STAT ${ }^{\circledR}$ user's guide, version 6, vol. 2, 4th edition, Gary, NC: SAS Institute Inc.; 1990, 1686 pp..

[15] Lehrer AR, Brown MB, Schindler H, Holzer Z, Larson B. Paternity tests in multisired beef herds by blood grouping. Acta Vet Scand 1977;18:433-41.

[16] Levis DG. Management strategies for pen-mating female pigs. University of Nebraska publication EC 97-276-B, Institute of
Agriculture and Natural Resources; 199718 pp.http://ianrpubs. unl.edu/Swine/ec276.pdf.

[17] Price EO. Male sexual behaviour. In: Price EO, editor. Farm animal behaviour Vet Clin North Am, vol. 3. Food Animal Practice; 1987. p. 405-22.

[18] de Blockey MA. Observations on group-mating of bulls at pasture. Appl Anim Ethol 1979;5:15-34.

[19] Grigoriadis DF, Edwards SA, English PR, Davidson FM. The effect of reducing the number of boars, according to their sexual status, on the reproductive efficiency in a dynamic service system. Epitheorese Zootehnikes Epistemes 2004;32:63-73.

[20] Danish Meat Association. Orne: Reproduktion og brug. Info Svin; 2006 www.infosvin.dk/index.aspx?id=fdb77dcf-17064a02-be00-a2fefd53d943, 3 pp.

[21] Frangez R, Gider T, Kosec M. Frequency of boar ejaculate collection and its influence on semen quality, pregnancy rate and litter size. Acta Veterinaria Brno 2005;74:265-73.

[22] Hemsworth PH, Price EO, Tilbrook AJ. Influence of the sexual motivation of the boar on the sexual partner preferences of oestrous gilts. Appl Anim Behav Sci 1992;33:209-15.

[23] Levis DG. Evaluating replacement boars for sexual behaviour. Agri-Practice 1984;5:23-6.

[24] Wodzicka-Tomaszewska M, Kilgour R, Ryan M. "Libido" in the larger farm animals: a review. Appl Anim Etol 1981;7:20338.

[25] Hemsworth PH, Tilbrook AJ. Sexual behaviour of male pigs. Hormones Behav 2007;52:39-44.

[26] Levis DG, Ford JJ, Christenson RK. An evaluation of three methods for assessing sexual behaviours in boars. J Anim Sci 1997;75:348-55.

[27] Kongsted AG. Relation between reproduction performance and indicators of feed intake, fear and social stress in commercial herds with group-housed non-lactating sows. Livest Sci 2006;101:46-56.

[28] Hultén F, Wallenbeck A, Rydhmer L. Brunst under diperioden vid grupphållning av sugar. In: Sammanfattningar av föredrag och postrar, Ekologisk Lantbruk konferens 22-23 November 2005, SLU: Uppsala; 2005, www.cul.slu.se/information/publik/ konfrapport2005.pdf, pp. 297-98.

[29] Rydhmer L, Wallenbeck A, Hultén F. Reproduction and maternal behaviour in organic piglet production. In: Proceedings of NJFseminar no. 369, Organic farming for a new millennium; 2005. p. 207-10.

[30] Jultved CR. Rapport over P-rapporternes resultater oktober 2005. Notat 0532. Landsudvalget for Svin, Dansk Landbrugsrådgivning, Landscentret Svin; 2005, 4 pp. 